\title{
AdVANCEd Gasification By-Product Utilization
}

\author{
ANNUAL TECHNICAL REPORT \\ for period
}

1 September 2004 through 31 August 2005

prepared by

Dr. Rodney Andrews, Ms. Aurora Rubel, Dr. Jack Groppo, Dr. Ari Geertsema University of Kentucky Center for Applied Energy Research

\author{
Dr. Frank Huggins \\ University of Kentucky Center for Fossil Fuel Science
}

Dr. M. Mercedes Maroto-Valer, Ms. Brandie M. Markley, Dr. Harold Schobert Pennsylvania State University Energy Institute

\author{
issued \\ February 2006 \\ for contract \\ DE-FG26-03NT41795 \\ submitted by \\ Lexington, KY
}

University of Kentucky Research Foundation 


\section{Disclaimer}

This report was prepared as an account of work sponsored by an agency of the United States Government. Neither the United States Government nor any agency thereof, nor any of their employees, makes any warranty, express or implied, or assumes any legal liability or responsibility for the accuracy, completeness, or usefulness of any information, apparatus, product, or process disclosed, or represents that its use would not infringe privately owned rights. Reference herein to any specific commercial product, process, or service by trade name, trademark, manufacturer, or otherwise does not necessarily constitute or imply its endorsement, recommendation, or favoring by the United States Government or any agency thereof. The views and opinions of authors expressed herein do not necessarily state or reflect those of the United States Government or any agency thereof. 


\begin{abstract}
With the recent passing of new legislation designed to permanently cap and reduce mercury emissions from coal-fired utilities, it is more important than ever to develop and improve upon methods of controlling mercury emissions. One promising technique is carbon sorbent injection into the flue gas of the coal-fired power plant. Currently, this technology is very expensive as costly commercially activated carbons are used as sorbents. There is also a significant lack of understanding of the interaction between mercury vapor and the carbon sorbent, which adds to the difficulty of predicting the amount of sorbent needed for specific plant configurations.
\end{abstract}

Due to its inherent porosity and adsorption properties as well as on-site availability, carbons derived from gasifiers are potential mercury sorbent candidates. Furthermore, because of the increasing restricted use of landfilling, the coal industry is very interested in finding uses for these materials as an alternative to the current disposal practice.

The results of laboratory investigations and supporting technical assessments conducted under DOE Subcontract No. DE-FG26-03NT41795 are reported for the period September 1, 2004 to August 31, 2005. This contract is with the University of Kentucky Research Foundation, which supports work with the University of Kentucky Center for Applied Energy Research and The Pennsylvania State University Energy Institute. The worked described was part of a project entitled “Advanced Gasification By-Product Utilization”. This work involves the development of technologies for the separation and characterization of coal gasification slags from operating gasification units, activation of these materials to increase mercury and nitrogen oxide capture efficiency, assessment of these materials as sorbents for mercury and nitrogen oxides, and characterization of these materials for use as polymer fillers. 


\section{TABLE OF CONTENTS}

Abstract

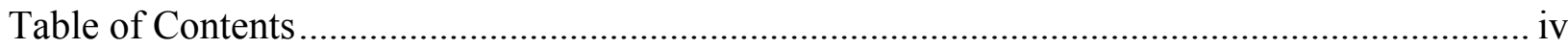

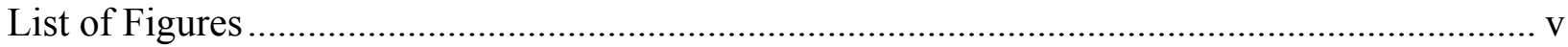

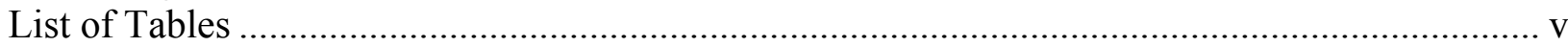

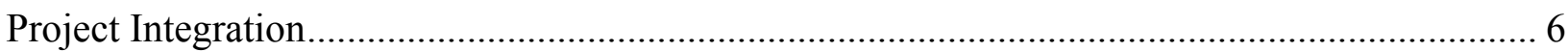

Project Schedule

Work Performed at The University of Kentucky .................................................................. 7

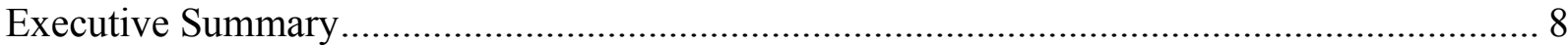

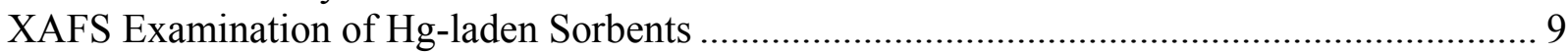

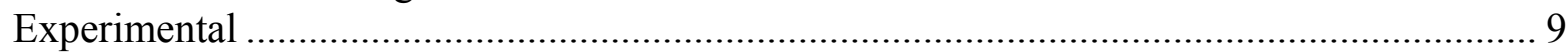

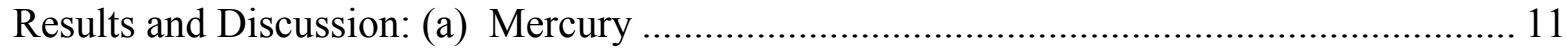

Results and Discussion: (b) Sulfur and Chlorine ............................................................. 15

Reactor System for Testing of Hg Adsorption Potential in Simulated Flue Gas ..................... 18

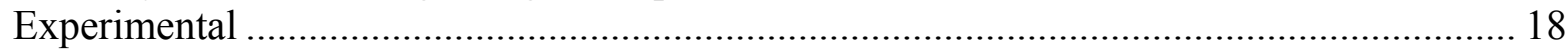

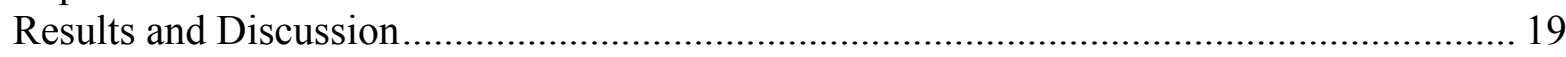

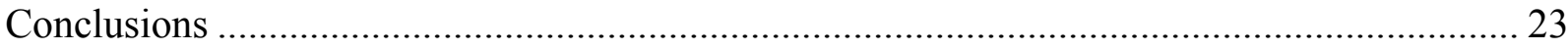

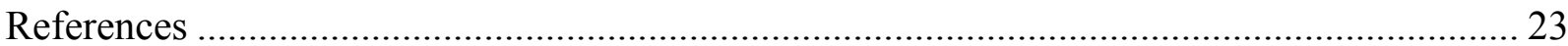

Work Performed at The Pennslyvania State University …………………………………..... 25

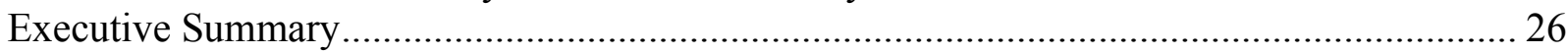

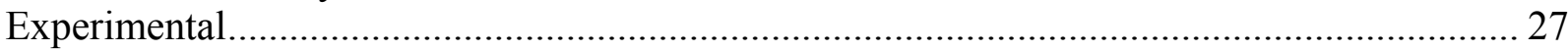

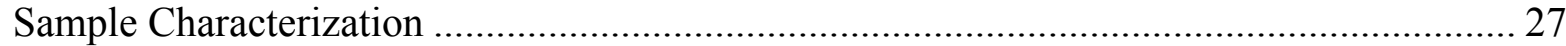

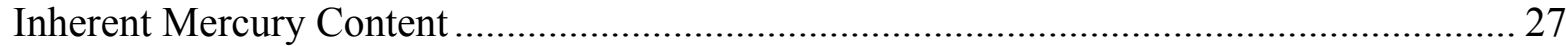

Major and Minor Elemental Ash Chemistry …………...................................................... 27

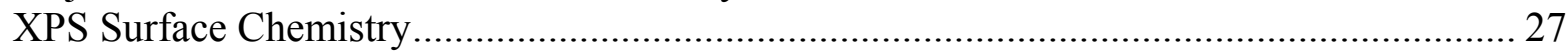

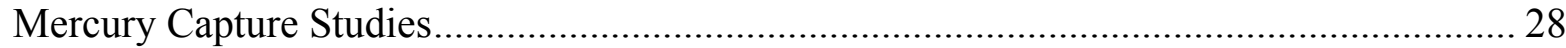

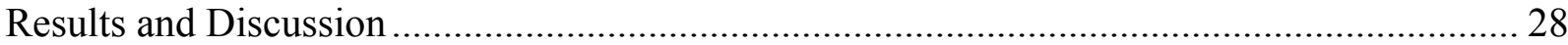

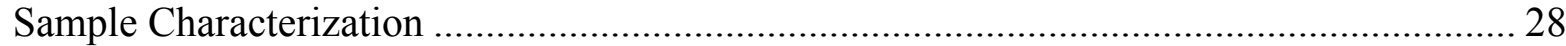

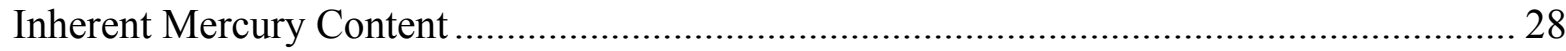

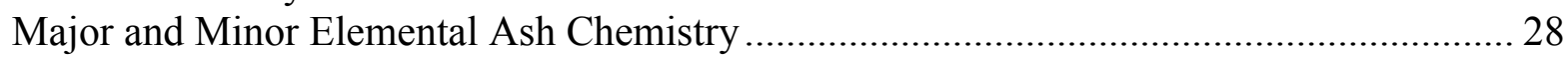

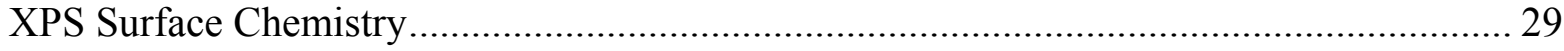

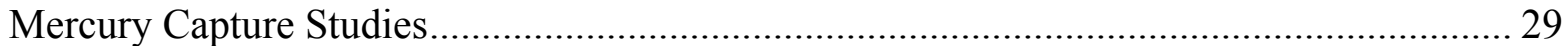

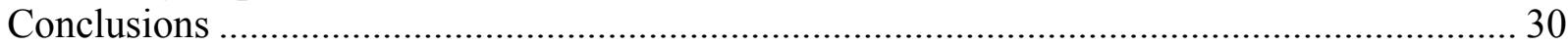

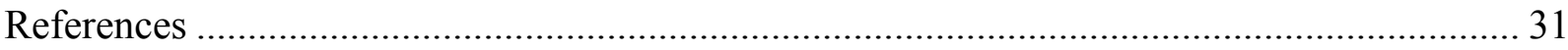

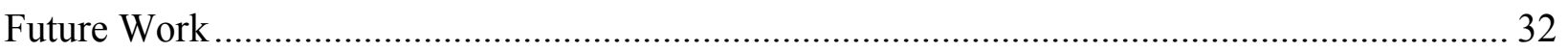




\section{LIST OF FIGURES}

\begin{tabular}{|l|l|c|}
\hline & Title & Page \\
\hline Figure 1.1 & Mercury L LII-edge XANES spectra for sorbents and for cubic HgS & 12 \\
\hline Figure 1.2 & $\begin{array}{l}\text { Definition and determination of the IPD parameter for Hg XANES } \\
\text { spectra }\end{array}$ & 12 \\
\hline Figure 1.3 & $\begin{array}{l}\text { EXAFS-RSF spectra for HgS (red), and the two carbonaceous } \\
\text { sorbents. }\end{array}$ & 13 \\
\hline Figure 1.4 & $\begin{array}{l}\text { Example of least-squares fitting of the } \mathrm{k}^{3} \text {-weighted chi data region } \\
\text { for Hg in sample (20+21) based on FEFF back-scattering } \\
\text { parameters }\end{array}$ & 13 \\
\hline Figure 1.5 & $\begin{array}{l}\text { Sulfur XANES spectra for the two sorbent samples and for the } \\
\text { control sample }\end{array}$ & 16 \\
\hline Figure 1.6 & $\begin{array}{l}\text { Chlorine XANES spectra for the two sorbent samples and for the } \\
\text { control sample. }\end{array}$ & 22 \\
\hline Figure 2.1 & Original CAER mercury adsorption testing system & 22 \\
\hline Figure 2.2 & $\begin{array}{l}\text { Reactor system for the testing of gasifier by-products using } \\
\text { simulated flue gas }\end{array}$ & $\begin{array}{l}\text { Comparison of Hg analyzers monitoring simulated flue gas } \\
\text { through bypass }\end{array}$ \\
\hline Figure 2.3 & Concentration of Hg in standard carbon versus time & 22 \\
\hline Figure 2.4 & & 22 \\
\hline
\end{tabular}

\section{LIST OF TABLES}

\begin{tabular}{|l|l|c|}
\hline Table 1.1 & $\begin{array}{l}\text { XAFS IPD Values and Parameters from least-squares coordination } \\
\text { shell fitting }\end{array}$ & 15 \\
\hline Table 3.1 & $\begin{array}{l}\text { ICP spectrochemical analyis reported in oxide percentages by } \\
\text { weight (as-received) }\end{array}$ & 29 \\
\hline Table 3.2 & Concentration of elements detected on powders & 29 \\
\hline Table 3.3 & Mercury capture analysis & 30 \\
\hline
\end{tabular}




\section{PROJECT INTEGRATION}

This University Coal Research project is a collaborative effort between the University of Kentucky Center for Applied Energy Research (CAER), The Pennsylvania State University Energy Institute, and industry collaborators supplying gasifier char samples. Principally, the objectives of the work at the CAER were to investigate the potential use of gasifier slag carbons as a source of low cost sorbent for $\mathrm{Hg}$ and $\mathrm{NO}_{\mathrm{X}}$ capture from combustion flue gas and as a source of activated carbons. Primary objectives are to determine the relationship of surface area, pore size, pore size distribution, and mineral content on $\mathrm{Hg}$ storage of gasifier carbons and to define the site of $\mathrm{Hg}$ storage. The ability of gasifier slag carbon to capture $\mathrm{NO}_{\mathrm{X}}$ and the effect of $\mathrm{NO}_{\mathrm{X}}$ on $\mathrm{Hg}$ adsorption are secondary goals. Since gasifier chars have already gone through a devolatilization process in a reducing atmosphere in the gasifier, they only require to be activated to be used as activated carbons. Therefore, the principal objective of the work at PSU is to characterize and utilize gasification slag carbons for the production of activated carbons and other carbon fillers. Testing the $\mathrm{Hg}$ and $\mathrm{NO}_{\mathrm{X}}$ adsorption potential of these activated gasifier carbons is a secondary objective of this work.

In the past year, samples supplied by UK to PSU have subsequently been characterized at PSU for sorption characteristics and independently tested for Hg-capture. The UK group has proceeded with chemical activation of the most promising samples, and the PSU group is scheduled to begin steam (thermal) activation of these samples. Subsequently, the activated samples will be tested at $\mathrm{UK}$ for $\mathrm{Hg}$-sorption and $\mathrm{NO}_{\mathrm{x}}$ capture in a simulated flue gas environment. As the project progresses, the activated carbons produced at PSU will be supplied to UK for further testing and UK will provide additional char samples and sub-samples to PSU for activation and characterization. The division of tasks reduces overall overlap while still assuring redundant characterization and assessment to give an accurate view of the variability inherent to these types of materials.

\section{PROJECT SCHEDULE}

The project is progressing on schedule. The remainder of the sample activation will be carried out in early 2006, with completion to remain as scheduled. Remaining tasks to be accomplished are described individually in each of the technical sections as well as summarized in the Future Work section. 
WORK PERFORMED AT THE UNIVERSITY OF KENTUCKY 


\section{EXECUTIVE SUMMARY}

A number of different processes for control of $\mathrm{Hg}$ emissions from electric power generation are being investigated which involve the use of a sorbent, usually activated carbon, as the primary $\mathrm{Hg}$ capture step. One problem associated with the use of activated carbon for $\mathrm{Hg}$ flue gas control is its high cost. Two approaches to reducing these costs are reducing the required carbon to $\mathrm{Hg}$ ratio or the use of a low cost alternative sorbent. A potential source of less expensive sorbent material is the unburned carbon in gasifier char, which is the focus of this study. The CAER has studied the relationship between $\mathrm{Hg}$ capture and fly-ash characteristics and have demonstrated several fundamental relationships which should apply to gasifier chars. Highly significant correlations were found between the magnitude of $\mathrm{Hg}$ capture and $\mathrm{C}$ content for fly ashes, type of fly ash carbon, and the BET surface area. All these factors point to the possible utilization of high carbon gasifier char for $\mathrm{Hg}$ capture.

Mercury, sulfur and chlorine XAFS spectra have been collected for two samples of differing Hg contents and a control sample. Analysis of the $\mathrm{Hg}$ XAFS data would suggest that the $\mathrm{Hg}$ is bound predominantly to $\mathrm{S}$; however, it should be noted that $\mathrm{Cl}$ is not eliminated by these data because of its proximity to sulfur in the periodic table and its similar X-ray scattering properties. In addition, the data indicate that the $\mathrm{Hg}$ coordination and bond length to sulfur are significantly reduced compared to that in cubic $\mathrm{HgS}$. However, this may be a result of the mercury being bound at the surface of the sorbent rather than in a well-defined crystal structure. Sulfur and chlorine XANES spectra indicate that the sulfur and chlorine speciation between the two sorbent samples is very different. In the one sample, (22), sulfur is present mostly as metal sulfides, whereas the other sorbent sample, $(20+21)$, contains elemental sulfur, thiophene and sulfate forms as major forms and very little, if any, sulfur as metal sulfide. Preliminary analysis of the chlorine XANES data indicates the possible presence of organochlorine compounds; however, this awaits confirmation depending on the calibration of the Cl XANES spectra.

A reactor system has been developed for testing $\mathrm{Hg}$ capture under simulated flue gas conditions. The final configuration of the reactor system is capable of measuring the Hg uptake over extended periods with minimal interference from other constituents in the gas phase. 


\section{XAFS EXAMINATION OF HG-LADEN SORBENTS Experimental}

Three samples of carbonaceous solids were received for analysis by $\mathrm{Hg}$ X-ray absorption fine structure (XAFS) spectroscopy. These samples are as follows:

Sample A1(run 20+21): Carbonaceous solid with high loading of $\mathrm{Hg}$

Sample A2(run 22): $\quad$ Carbonaceous solid with light loading of $\mathrm{Hg}$

Sample A1(run 26): $\quad$ Control sample with no Hg loading

XAFS data were also obtained on the $\mathrm{S}$ and $\mathrm{Cl}$ species present in these samples.

The samples were subjected to mercury $\mathrm{L}_{\mathrm{III}}$-edge XAFS spectroscopy at both beam-line X-18B at the National Synchrotron Light Source (NSLS), Brookhaven National Laboratory, NY, and beam-line 11-2 at the Stanford Synchrotron Radiation Laboratory (SSRL), Stanford University, CA. The data obtained at the latter facility were significantly better in terms of both resolution and signal/noise ratio and the results described herein are based only on the data obtained at SSRL, although there was good agreement between the data obtained at both laboratories. Sulfur and chlorine K-edge XAFS data were obtained at beam-line X-19A at NSLS.

Mercury $\mathrm{L}_{\mathrm{III}}$-edge XAFS spectra were obtained at SSRL using a silicon (220) double crystal monochromator over the energy range from 12,200 to as much as $13,000 \mathrm{eV}$. The spectra were acquired in fluorescent geometry using a high signal/noise throughput, 30-element Ge detector (Cramer et al., 1988), Soller slits and a 6u Ga filter (Stern and Heald, 1979), and multiple scanning. The net effect of these experimental arrangements was the collection of superior quality XAFS spectra, despite the relatively low $\mathrm{Hg}$ content in sample (22). Samples of $\mathrm{HgS}$ (metacinnabar), yellow $\mathrm{HgO}$, red $\mathrm{HgO}, \mathrm{HgNO}_{3}$, and $\mathrm{Hg}$ metal were also collected at the same session under similar conditions. However, a standard transmission detector and Lytle fluorescence detector (Lytle et al., 1984) were used for the XAFS measurements on the standard $\mathrm{Hg}$ compounds. Primary calibration of the energy scale was achieved by running the spectrum of metallic mercury in a simultaneous transmission experiment behind the fluorescent experiment on the carbonaceous solids. The major peak in the derivative $\mathrm{Hg} \mathrm{L}_{\mathrm{III}}$-edge XANES spectrum of elemental $\mathrm{Hg}$ was assumed to occur at 12,284 eV. 
Sulfur and chlorine K-edge XAFS spectra were obtained at NSLS using a silicon (111) double crystal monochromator over the energy range from $2,400 \mathrm{eV}$ to $2,900 \mathrm{eV}$. This region included the absorption edges for both $\mathrm{S}$ and $\mathrm{Cl}$ at $2,472 \mathrm{eV}$ and 2,825 eV, respectively. The spectra were acquired in a modified Lytle fluorescent detector using a PIPS detector to measure the fluorescent $\mathrm{X}$ radiation. Helium was employed as the sample chamber flush gas. Primary calibration of the energy scale for both $\mathrm{S}$ and $\mathrm{Cl} \mathrm{K}$-edges was achieved by means of a pellet of SOMAR mix containing $2 \mathrm{wt} \%$ of elemental sulfur. The zero-point of energy was assumed to occur at the main peak position in the sulfur K-edge XAFS spectrum of elemental sulfur. Unfortunately, no $\mathrm{NaCl}$ was available to calibrate the position of the $\mathrm{Cl} \mathrm{K}$-edge precisely so the elemental sulfur calibration was also used to calibrate the position of the $\mathrm{Cl} \mathrm{K}$-edge.

Data analysis followed conventional practice (Eisenberger and Kincaid, 1978, Lee et al., 1981, Brown et al., 1988, Koningsberger and Prins, 1988) in that the energy scales of the carbonaceous sorbents were first adjusted according to the $\mathrm{Hg} \mathrm{L}_{\mathrm{III}}-$ edge position in elemental $\mathrm{Hg}$. Then the spectral data were normalized to unit edge-step and separate X-ray absorption near-edge structure (XANES) and extended X-ray absorption fine structure (EXAFS) regions were obtained from the normalized XAFS data. The XANES region is used as a fingerprint for the $\mathrm{Hg}$ species under investigation. The only manipulation done on this region of the spectrum was to smooth the data and determine the first derivative of the spectrum in order to estimate the inflection point difference (IPD) parameter (Huggins et al., 1999). As discussed in detail elsewhere (Huggins et al., 1999, 2003), this parameter is a direct probe of the local bonding of the ligand atoms to the central $\mathrm{Hg}^{2+}$ ion and its value often reflects the element to which the $\mathrm{Hg}^{2+}$ is bound. The EXAFS region was converted from a real space to a reciprocal space (k-space) representation to yield the chi vs. $\mathrm{k}$ spectrum. The chi spectrum was then weighted by $\mathrm{k}^{3}$ and subjected to a Fourier transform to yield a radial structure function (RSF), which is basically a one-dimensional representation of the structure local to the X-ray absorbing $\mathrm{Hg}$ atom.

Data analysis for sulfur and chlorine was limited to generating the XANES spectra for both elements as the EXAFS region could not be successfully processed due to the limited energy range afforded to the two elements. 


\section{Results and Discussion: (a) Mercury}

The size of the $\mathrm{Hg} \mathrm{L}_{\mathrm{III}}$ absorption edge observed for the three samples was quite different, and clearly reflected the differences in $\mathrm{Hg}$ concentration of the samples. The control sample exhibited no step whatsoever at 12,284 eV and therefore any mercury in this sample is below the limit of detection of the XAFS experiment (estimated to be significantly less than $1.0 \mathrm{ppm}$ ). The other two samples exhibited a very obvious absorption edge at 12,284 eV. The XANES regions for these two samples, along with that of cubic $\mathrm{HgS}$ (metacinnabar), are shown in Figure 1.1.

The spectra of the two sorbents are closely similar and appear most similar to that of HgS of any of the Hg compounds in our database (q.v. Huggins et al., 2003). However, there are significant differences between the spectrum of $\mathrm{HgS}$ and those of the sorbents. There are slight shifts in energy of the absorption edge, the broad peaks above the edge, and the inflection points on the absorption edge. However, when the first-derivative spectra are generated (Figure 1.2) and the inflection point differences, IPD, are compared, the IPD values are found to be virtually the same, $7.6 \pm 0.2 \mathrm{eV}$, for both sorbents and for $\mathrm{HgS}$, indicating that $\mathrm{S}^{2-}$ anions most likely surround the $\mathrm{Hg}^{2+}$ cation in the sorbents.

Both similarities and differences are also seen when the EXAFS/RSF spectra of the two sorbent materials and that of $\mathrm{HgS}$ are compared. This comparison is shown in Figure 1.3. The peak in the RSF spectrum occurs at about $2.05 \AA$ for cubic HgS, but is displaced by about $0.15 \AA$ to shorter distance for the carbonaceous sorbents. Such displacements have been noted previously for S-based carbonaceous sorbents (Huggins et al., 2003). 


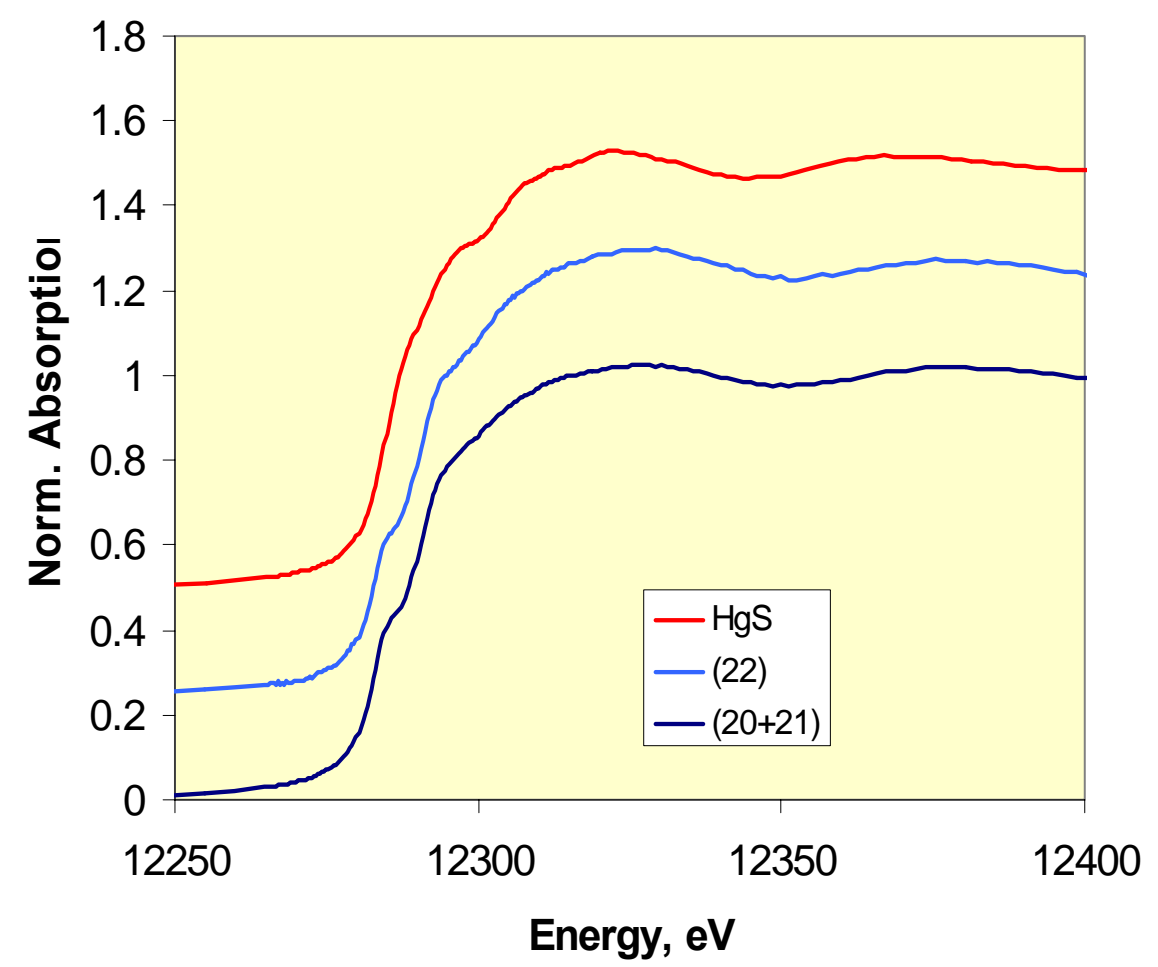

Figure 1.1: Mercury $L_{I I I}$-edge XANES spectra for sorbents and for cubic HgS.

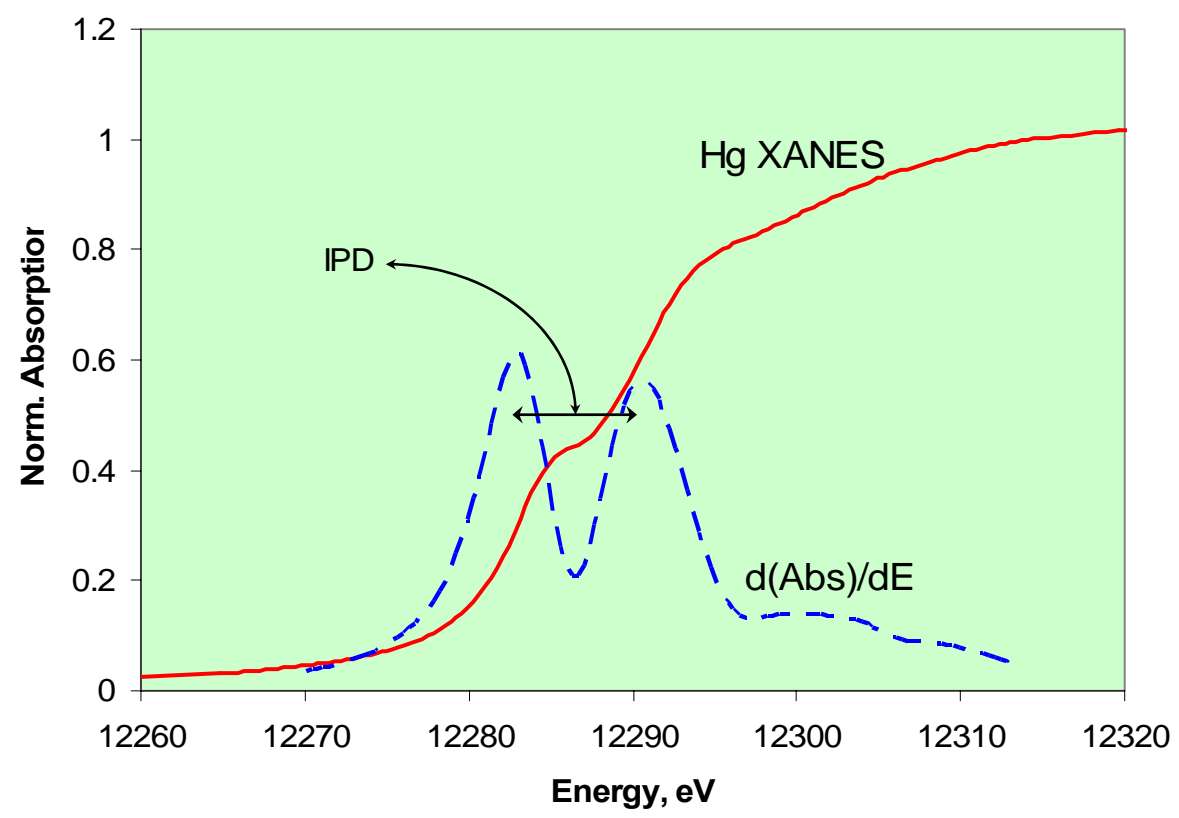

Figure 1.2: Definition and determination of the IPD parameter for Hg XANES spectra. The inflection point difference (IPD) is measured as the separation in energy of the double peak that is obtained by differentiating the $\mathrm{Hg}$ XANES spectrum. The data are smoothed before being differentiated, and as discussed elsewhere (Huggins et al., 1999), normally the measurement is made using the second derivative. 


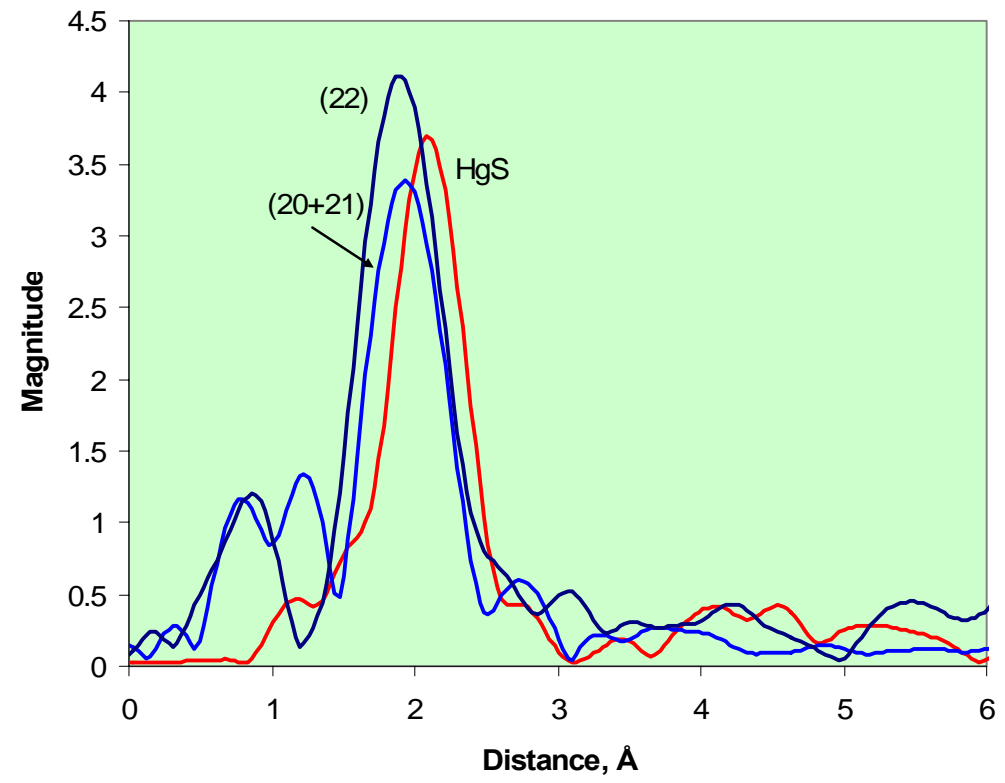

Figure 1.3: EXAFS-RSF spectra for HgS (red), and the two carbonaceous sorbents, one with a high loading of $\mathrm{Hg}(20+21)$ (light blue), and the other with a much lighter loading of $\mathrm{Hg}$ (22) (dark blue). Note that the peak position of the main peak is displaced for the sorbent samples compared to that for cubic HgS. The other peaks are mostly, if not entirely, artifacts.

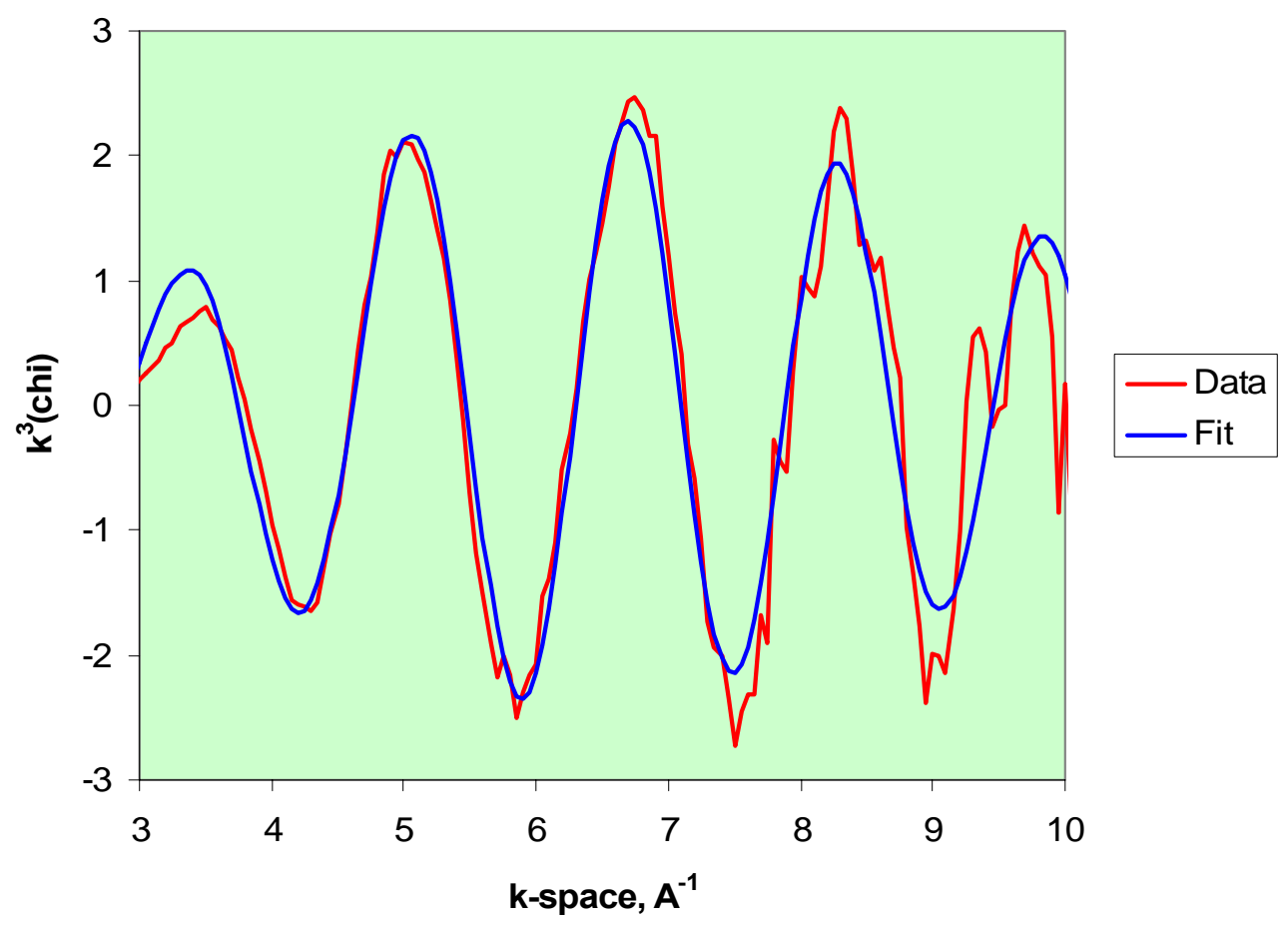

Figure 1.4: Example of least-squares fitting of the $k^{3}$-weighted chi data region for $\mathrm{Hg}$ in sample $(20+21)$ based on FEFF back-scattering parameters derived from the spectrum of cubic HgS. 
Some more advanced fitting of the EXAFS-RSF data has been attempted using least-squares fitting based on FEFF 6 simulation. Basically, this is a procedure that attempts to calculate the EXAFS region of the spectrum based on established X-ray scattering data for different combinations of elements. In this case, we calculated the FEFF X-ray scattering data for $\mathrm{HgS}$ based on its known crystal structure (space group F $-43 \mathrm{~m}, \mathrm{a}_{0}=5.8517 \AA$ ) using the data provided by Wykcoff (1960). The least-squares fitting was performed using a software package developed by S. Webb of SSRL. Once we had derived various fitting parameters based on the EXAFS data for HgS, we then refined such parameters based on the spectra obtained for the two sorbents. An example of this kind of fitting is shown in Figure 1.4 and the results are summarized in Table 1.1.

From such fitting, one may derive values for the average Hg-nearest neighbor distance (R), the approximate coordination number $(\mathrm{N})$, the Debye-Waller factor $\left(\sigma^{2}\right)$ for the $\mathrm{Hg}-\mathrm{X}$ bond, and the energy offset $\left(\mathrm{E}_{0}\right)$. It is clear that, based on the assumption that sulfide anions are the nearest neighbor to the $\mathrm{Hg}$ atoms, the distance, coordination number, and Debye-Waller factor are reduced for the $\mathrm{Hg}$ bound to the carbonaceous solid compared to the standard material. The difference of $0.12 \AA$ in bond length is a significant difference and must reflect the difference between the 3-dimensional bonding experienced by $\mathrm{Hg}$ in $\mathrm{HgS}$ and the 2-dimensional surface bonding experienced by $\mathrm{Hg}$ in the sorbents. It is well known that the same $\mathrm{M}-\mathrm{X}$ bond is often significantly shorter in structures of lower coordination number. Interestingly, based on the fitting results in Table 1.1, the coordination number is clearly reduced for the $(20+21)$ sample compared to that for the other two samples. 
Table 1.1: XAFS IPD Values and Parameters from least-squares coordination shell fitting

\begin{tabular}{|c|c|c|c|c|c|c|c|c|}
\hline Sample & IPD, eV & Fit* $^{*}$ & $\mathrm{~S}_{0}^{2 * *}$ & $\mathbf{N}^{* *}$ & $E_{0}, e V$ & $\mathbf{R}, \AA$ & $\sigma^{2}$ & R Factor \\
\hline \multirow[t]{2}{*}{ HgS, cubic } & 7.6 & $\mathbf{R}$ & 0.23 & 4 & 5.0 & 2.51 & 0.013 & 0.040 \\
\hline & & k & 0.21 & 4 & 5.4 & 2.51 & 0.012 & 0.095 \\
\hline \multirow[t]{2}{*}{$(20+21)$} & 7.6 & $\mathbf{R}$ & 0.23 & 2.1 & 3.3 & 2.39 & 0.007 & 0.016 \\
\hline & & k & 0.21 & 2.2 & 3.6 & 2.39 & 0.007 & 0.079 \\
\hline \multirow[t]{2}{*}{ (22) } & 7.5 & $\mathbf{R}$ & 0.23 & 3.5 & 3.0 & 2.39 & 0.010 & 0.037 \\
\hline & & k & 0.21 & 3.5 & 3.6 & 2.39 & 0.009 & 0.221 \\
\hline
\end{tabular}

* Least-squares fitting performed on RSF spectrum (R), over range from 1.4-2.7 $\AA$, or on chi spectral data $(\mathrm{k})$, over range from $3-10 \AA^{-1}$. The results are reasonably consistent between the two types of fit. ${ }^{*} \mathrm{~S}_{0}{ }^{2}$ assumed variable, $\mathrm{N}$ assumed constant for fitting of $\mathrm{HgS}$ spectra; $\mathrm{S}_{0}{ }^{2}$ assumed constant, $\mathrm{N}$ assumed variable for fitting of $\mathrm{Hg}$ sorbents.

The $\mathrm{R}$ factor is a measure of the quality of the fit and is determined by the signal/noise ratio of the data as well as the adequacy of the fit.

\section{Results and Discussion: (b) Sulfur and Chlorine}

Sulfur and chlorine XANES spectra are shown in Figures 1.5 and 1.6, respectively. The sulfur XANES spectra of the two sorbent samples are very different; however, the S XANES spectrum of sample $(20+21)$ is closely similar to that of the control sample. It would appear that the control sample contains slightly more elemental sulfur and thiophenic sulfur forms and slightly less sulfate than the sorbent sample $(20+21)$. The sorbent sample $(22)$ is quite different. The sulfur is largely present as one or more metal sulfides, with only very minor amounts of thiophenic and sulfate sulfur forms present and essentially no elemental sulfur. Without knowing more details of the preparation of these samples, it is not possible to speculate why these differences are observed.

The three chlorine XANES spectra are different one from another. Again, the control sample and the sorbent sample $(20+21)$ appear to be most similar; however, the sharp peaks on the lowenergy side of the main absorption peak occur at different positions $(-4.8 \mathrm{eV}$ and $-3.6 \mathrm{eV}$, respectively) and are of significantly different intensity. The chlorine XANES spectrum of sorbent sample (22) is significantly weaker than those of the other two samples. However, the 
small sharp peak at low energy for this sample occurs at about the same position as the much larger sharp peak in the spectrum of sample $(20+21)$. The presence of these narrow peaks at this low energy indicates the presence of either organochlorine or hypochlorite $\left(\mathrm{OCl}^{-}\right)$compounds in the sorbent samples (Huggins and Huffman, 1995). Calibrated Cl XANES spectra need to be performed to distinguish these possibilities and to identify the main $\mathrm{Cl}$ species.

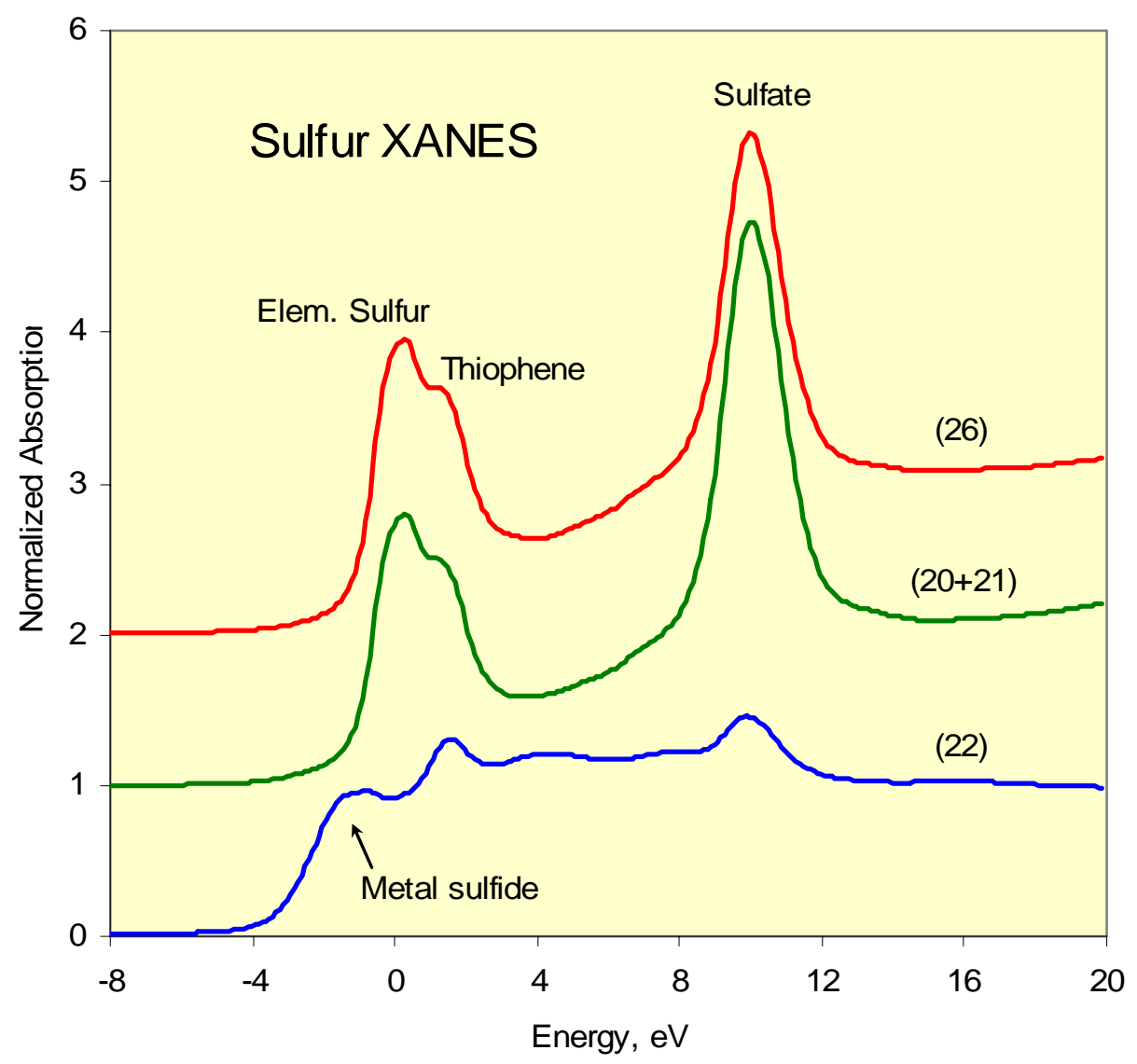

Figure 1.5: Sulfur XANES spectra for the two sorbent samples, (20+21) and (22), and for the control sample, (26). The peaks are identified as arising from elemental sulfur, thiophenic sulfur, sulfate sulfur and metal sulfide. The sulfur forms in (22) largely arise from metal sulfide, which is absent from the other two samples. The zero-point of energy corresponds to 2,472 eV. 


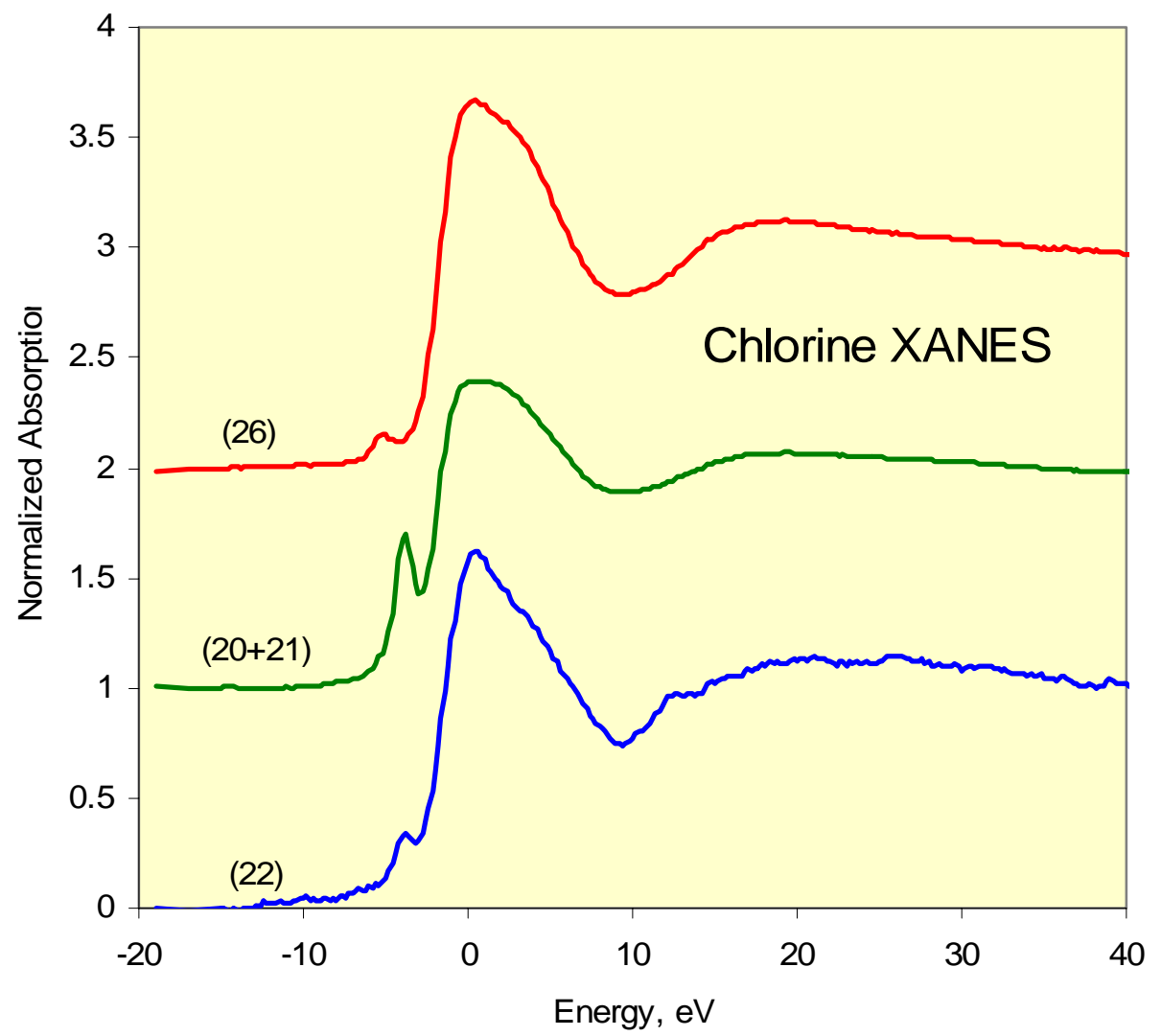

Figure 1.6: Chlorine XANES spectra for the two sorbent samples, (20+21) and (22), and for the control sample, (26). Note the presence of the sharp peak on the low-energy side of the main peak, especially for sample $(20+21)$. The zero-point of energy corresponds to 2,825 eV. 


\section{REACTOR SYSTEM FOR TESTING OF HG ADSORPTION POTENTIAL IN SIMULATED FLUE GAS}

\section{Experimental}

In order to test the gasifier by-product carbon in a simulated flue gas, the original adsorption testing system at the CAER was upgraded. The original Hg adsorption testing system is shown in Figure 2.1. Modifications to the system involved additional mass flow controllers, $\mathrm{a} \mathrm{SO}_{2}$ scrubber, $\mathrm{a} \mathrm{Hg}^{+2}$ to $\mathrm{Hg}^{0}$ conversion column, and a second $\mathrm{Hg}$ vapor analyzer. The original system was plumbed for the use of only one purge gas, air. In order to blend air with gas mixtures of $\mathrm{NO}$ in $\mathrm{N}_{2}$ and $\mathrm{SO}_{2}$ in $\mathrm{N}_{2}$, two additional mass flow controllers and corresponding gas lines were added for the blending of three gases before the $\mathrm{Hg}$ permeation device (Figure 2.2).

The CAER had two $\mathrm{Hg}$ vapor analyzers available to monitor $\mathrm{Hg}^{0}$ concentrations leaving the $\mathrm{Hg}$ permeation device and to measure the $\mathrm{Hg}$ concentration leaving the fixed bed adsorption reactor containing the test material. Both have limitation which had to be overcome for use in simulated flue gas containing $\mathrm{NO}$ and $\mathrm{SO}_{2}$. The two instruments are a Jerome $431 \mathrm{X}$ and a Mercury Instruments VM 3000 continuous Hg vapor analyzer. The Jerome 431X requires the collection of a gas sample in a gas collection bag before analysis. The limitations of this unit are that at the concentration of $\mathrm{Hg}$ vapor used in this study, it required regeneration after just a few analyses and it is extremely sensitive to moisture. Additionally, it has acid gas scrubbers which are not rated for the $\mathrm{NO}$ and $\mathrm{SO}_{2}$ concentrations used in this study and which become quickly saturated. The Mercury Instruments VM 3000 detects $\mathrm{Hg}^{0}$ concentrations by cold vapor atomic adsorption spectrometry (CVAAS). $\mathrm{SO}_{2}$ interferes with this method of detection. Both analyzers only detect $\mathrm{Hg}^{0}$. In the presence of reactive gases such as $\mathrm{NO}$ and $\mathrm{SO}_{2}$ especially in the presence of carbon, a possible catalyst, there is the possibility of conversion of $\mathrm{Hg}^{0}$ to $\mathrm{Hg}^{+2}$, which would not be detected. All these issues were addressed in the modification of the original system.

Both analyzers were connected to the simulated flue gas reactor and used to confirm $\mathrm{Hg}$ concentrations in the gas (Figure 2.2). The Jerome was used to check the starting and ending levels $\mathrm{Hg}^{0}$ in the gas leaving the $\mathrm{Hg}$ permeation cell and this was verified and compared with the $\mathrm{Hg}^{0}$ detected by the VM3000. During a run and after switching the simulated flue gas to the adsorption testing reactor, the VM3000 CEM was used. In order to address the limitations of 
this unit (interference by $\mathrm{SO}_{2}$ and $\mathrm{Hg}^{+2}$ in the gas), the gases from the reactor were passed through a column packed first with finely crushed $\mathrm{CaCO}_{3}$ followed by fine particles of $\mathrm{SnCl}_{2}$ (Figure 2.2). The $\mathrm{CaCO}_{3}$ was used to scrub the $\mathrm{SO}_{2}$ from the gas stream (Reaction 2.1 and 2.2) and the $\mathrm{SnCl}_{2}$ was used to reduce $\mathrm{Hg}^{+2}$ to $\mathrm{Hg}^{0}$ according to Reaction 2.3.

Reaction 2.1: $\mathrm{SO}_{2}+\mathrm{CaCO}_{3} \rightarrow \mathrm{CaSO}_{3}+\mathrm{CO}_{2}$

Reaction 2.2: $\mathrm{SO}_{2}+\mathrm{CaCO}_{3}+1 / 2 \mathrm{O}_{2}+\mathrm{H}_{2} \mathrm{O} \rightarrow \mathrm{CaSO}_{4} \cdot 2 \mathrm{H}_{2} \mathrm{O}+\mathrm{CO}_{2}$

Reaction 2.3: $\mathrm{Sn}^{+2} \mathrm{Cl}_{2}^{-}+\mathrm{Hg}^{+2} \rightarrow \mathrm{Sn}^{+4} \mathrm{Cl}_{4}^{-}+\mathrm{Hg}^{0}$

\section{Results and Discussion}

Figure 2.3 shows the results of a comparison of the $\mathrm{Hg}$ vapor concentrations detected by both analyzers using air only and simulated flue gas. Gases were passed through the $\mathrm{CaCO}_{3} / \mathrm{SnCl}_{2}$ column before the VM3000 CEM. Good comparisons were obtained at three different Hg vapor concentrations.

The final procedures for testing the gasifier carbons using the reactor system shown in Figure 2.3 were then establish by further testing to meet the goals of being able to run a sufficiently large sample in a reasonable amount of time. The constraints of the time factor were to capture sufficient mercury in the sorbent to get accurate and reproduce numbers for mercury in the solids by XRF. Figure 2.4 shows the results for mercury captured by the gasifer carbon A1 (see previous annual report) at 4 different time intervals. The 48 hour adsorption time was chosen as optimum for this study. This time would keep high mercury values for good sorbents within reasonable limits and yet enough mercury capture by poor sorbents for accurate analyses. The composition of the simulated flue gas was 125 ppm NO, $125 \mathrm{ppm} \mathrm{SO}_{2}$, with a balance of air. Gas flow rate through the system was $100 \mathrm{ml} / \mathrm{m}$ metered at room temperature and pressure. Sorbent load was $200 \mathrm{mg}$. The entire system was maintained at $60^{\circ} \mathrm{C}$. The system is now ready for determining the effect of $\mathrm{NO}$ and $\mathrm{SO}_{2}$ on the capture of mercury by the study gasifier carbons and testing is currently being done. 


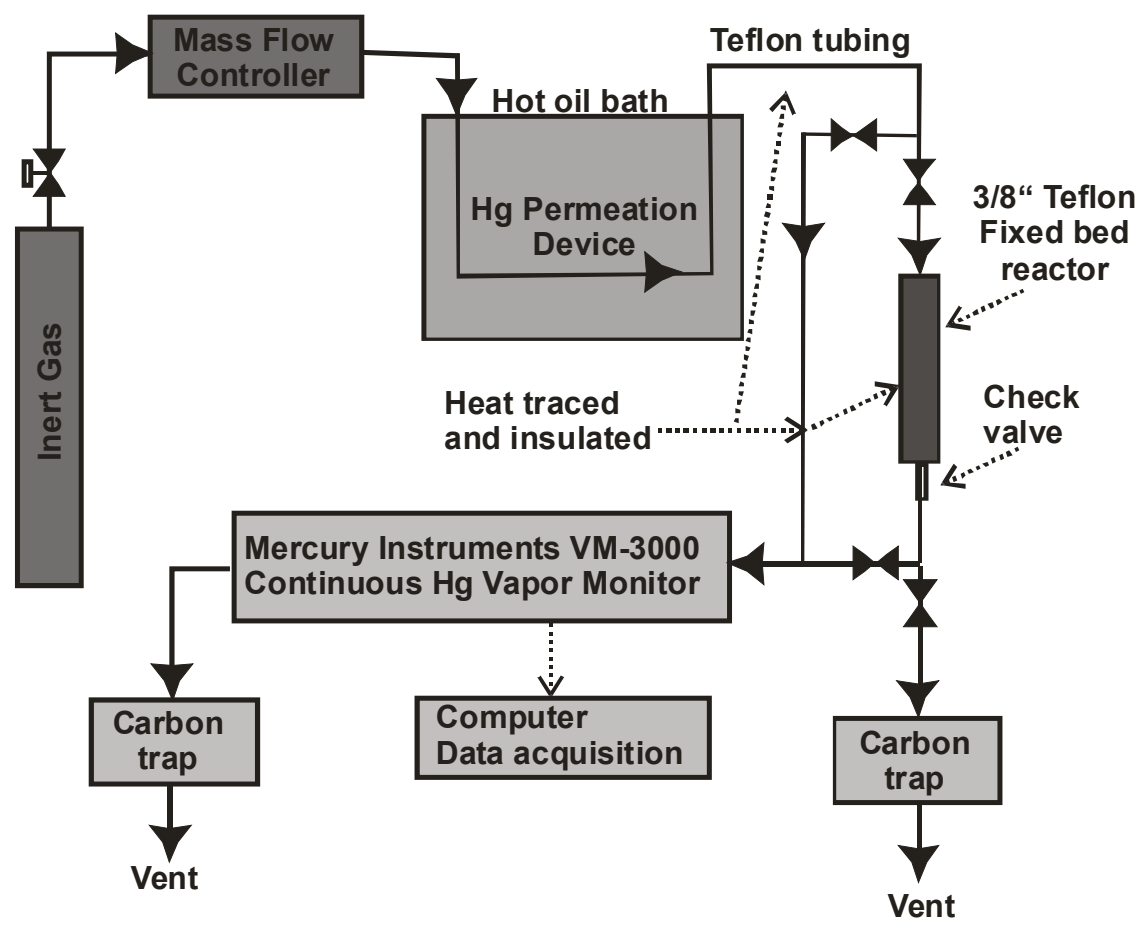

Figure 2.1. Original CAER mercury adsorption testing system 


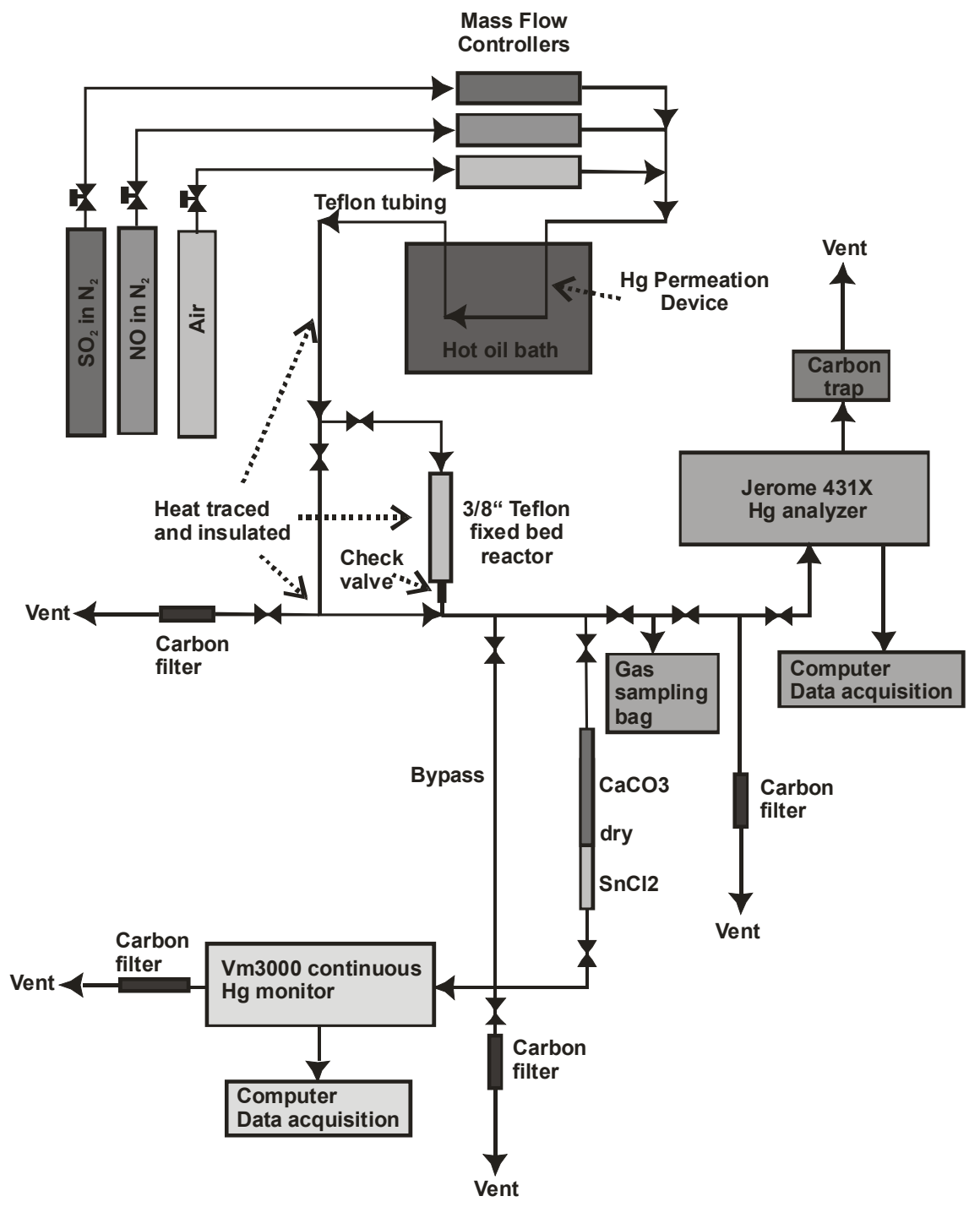

Figure 2.2. Reactor system for the testing of gasifier by-products using simulated flue gas 


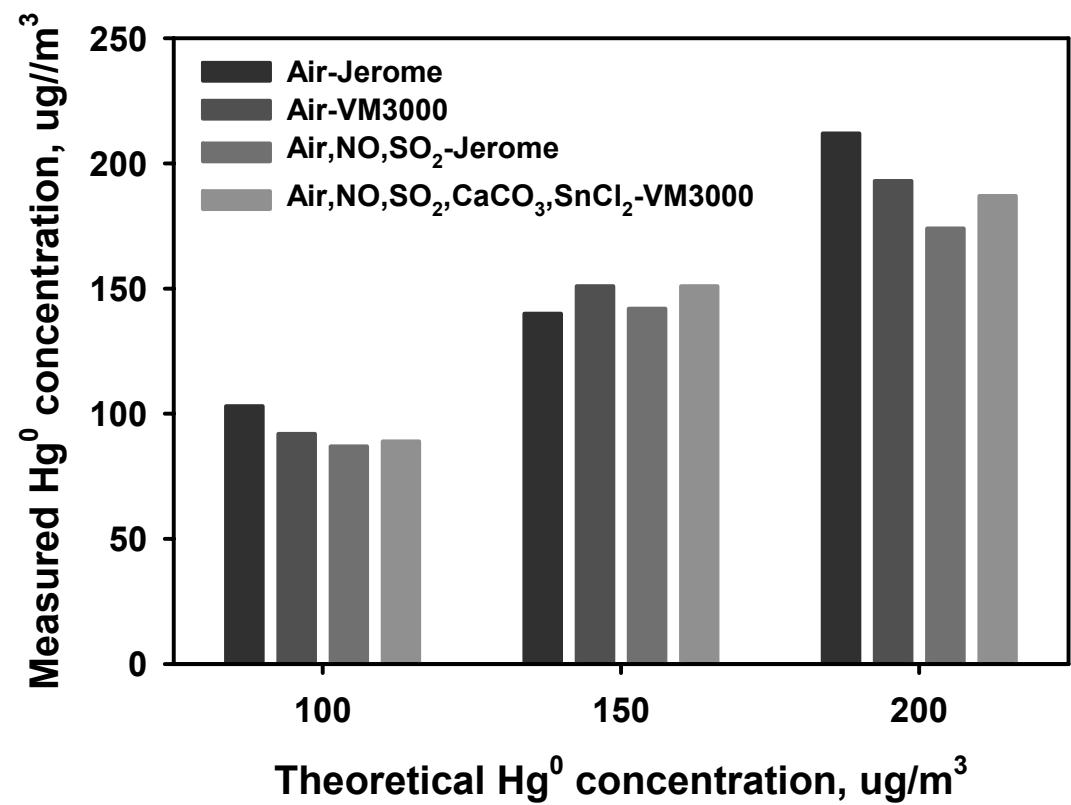

Figure 2.3. Comparison of $\mathrm{Hg}$ analyzers monitoring simulated flue gas through bypass.

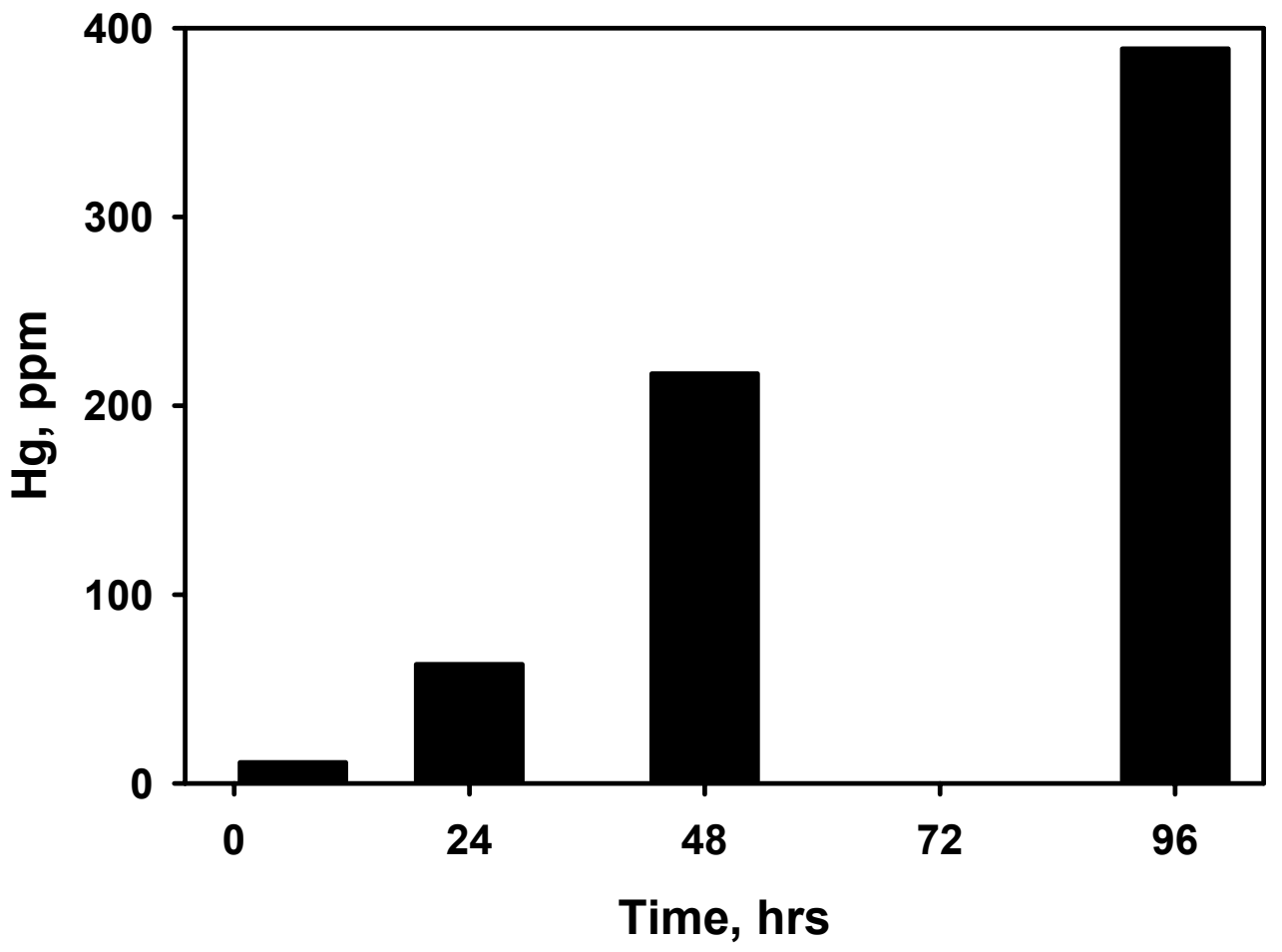

Figure 2.4. Concentration of $\mathrm{Hg}$ in standard carbon versus time. 


\section{CONCLUSIONS}

Mercury, sulfur and chlorine XAFS spectra have been collected for two samples of differing $\mathrm{Hg}$ contents and a control sample. Analysis of the $\mathrm{Hg}$ XAFS data would suggest that the $\mathrm{Hg}$ is bound predominantly to $\mathrm{S}$; however, it should be noted that $\mathrm{Cl}$ is not eliminated by these data because of its proximity to sulfur in the periodic table and its similar X-ray scattering properties. In addition, the data indicate that the $\mathrm{Hg}$ coordination and bond length to sulfur are significantly reduced compared to that in cubic HgS. However, this may be a result of the mercury being bound at the surface of the sorbent rather than in a well-defined crystal structure. Sulfur and chlorine XANES spectra indicate that the sulfur and chlorine speciation between the two sorbent samples is very different. In the one sample, (22), sulfur is present mostly as metal sulfides, whereas the other sorbent sample, $(20+21)$, contains elemental sulfur, thiophene and sulfate forms as major forms and very little, if any, sulfur as metal sulfide. Preliminary analysis of the chlorine XANES data indicates the possible presence of organochlorine compounds; however, this awaits confirmation depending on the calibration of the Cl XANES spectra.

A reactor system has been developed for testing simultaneous $\mathrm{Hg}$ capture and NOx conversion under simulated flue gas conditions. The final configuration of the reactor system is capable of measuring the $\mathrm{Hg}$ uptake over extended periods with minimal interference from other constituents in the gas phase. The system will subsequently be used to measure Hg-uptake on gasifier char carbons and activated chars in the coming year.

\section{REFERENCES}

Brown, Jr., G. E., Calas, G., Waychunas, G. A., and Petiau, J., (1988). X-ray absorption spectroscopy: applications in mineralogy and geochemistry, in: F.C. Hawthorne (ed.), Spectroscopic Methods in Mineralogy and Geology, Washington, DC, Chapter 11, 431-512.

Cramer, S. P., Tench, O., Yocum, N., and George, G. N., (1988). A 13-element germanium detector for fluorescent EXAFS. Nucl Instrum. Meth. A266, 586-591.

Eisenberger, P. and Kincaid, B. M., (1978). EXAFS: new horizons in structure determinations, Science, 200, 1441-1447.

Huggins, F. E., and Huffman, G. P., (1995). Chlorine in coal: an XAFS spectroscopic investigation. Fuel, 74, 556-569. 
Huggins, F. E., Yap, N., and Huffman, G. P., (1999). XAFS investigation of mercury sorption on carbon-based and other sorbent materials. Jpn. J. Appl. Phys. (Proc. Internat. Conf. SRMS-2, Kobe, Japan) 38 (Suppl. 38-1), 588-591.

Huggins, F. E., Yap, N., Huffman, G. P., and Senior, C. L., (2003). XAFS characterization of mercury captured from combustion gases on sorbents at low-temperature, Fuel Proc. Technol., 82, 167-196.

Koningsberger, D. C. and Prins, R., eds., (1988). X-ray absorption - principles, applications, techniques of EXAFS, SEXAFS, and XANES, Wiley, New York, NY.

Lee, P. A., Citrin, P. H., Eisenberger, P., and Kincaid, B. M., (1981). Extended x-ray absorption fine structure - its strengths and limitations as a structural tool, Rev. Mod. Phys., 53, 769808.

Lytle, F. W., Greegor, R. B., Sandstrom, D. R., Marques, E. C., Wong, J., Spiro, C. L., Huffman, G. P., and Huggins, F. E., (1984). Measurements of soft X-ray absorption spectra with a fluorescent ion chamber detector. Nucl. Instrum. Meth., 226, 542-548.

Stern,E. A and Heald, S. M., (1979). X-ray filter assembly for fluorescence measurements of Xray absorption fine structure, Rev. Sci. Instrum., 50, 1579-1582.

Wyckoff, R. W. G., (1960). Crystal Structures, Vol. 1, (2 $2^{\text {nd }}$ ed.) Wiley Interscience, New York. 
WORK PERFORMED AT THE PENNSLYVANIA STATE UNIVERSITY 


\section{EXECUTIVE SUMMARY}

On March 15, 2005, the U.S. Environmental Protection Agency (EPA) issued the Clean Air Mercury Rule designed to cap and reduce mercury emissions from coal-fired power plants ${ }^{1}$. When the rule is fully implemented as expected in 2018 , a reduction of nearly $70 \%$ is expected in annual utility mercury emissions ${ }^{1}$.

One promising way to control these emissions for compliance is by carbon sorbent injection into the flue gas of the coal-fired utilities. The annual cost of mercury control for this technology utilizing commercial activated carbons is estimated to be in the billions of dollars. Mercury concentrations in flue gas are very low (on the order of $1 \mathrm{ppb}$ by volume), flue gas is extremely complex in nature, the residence time of the carbon sorbent in the flue gas is very brief (only around $6 \mathrm{~s}$ ), and carbon sorbent selectivity for mercury is relatively poor leading to an overall need for carbon-to-mercury ratios from 1000:1 to 100,000:1 for various commercially available activated carbon sorbents ${ }^{2}$. Moreover, there is a lack of understanding of the interaction between mercury and the carbon sorbent, also making it very difficult to predict the amount of sorbent needed for a specific plant configuration.

Due to their inherent porosity and adsorption properties as well as on-site availability, fly ash carbons from coal-fired combustors or gasifiers are potential mercury sorbent candidates ${ }^{3}$. Furthermore, because of the increasing restricted use of landfilling, the coal industry is very interested in finding uses for these high carbon fly ashes as an alternative to the current disposal practice. Accordingly, the work in this study focuses on expanding the characterization of a gasification char provided by the Center for Applied Energy Research at the University of Kentucky, as well as testing the char for its ability to uptake mercury vapor. 


\section{EXPERIMENTAL}

\section{Sample Characterization}

The characterization conducted in this study involved a variety of methods that are discussed in the subsections below. The sample used throughout the work reported here is sample A1(run 26), as referenced above and the first year Annual Technical Report.

\section{Inherent Mercury Content}

Prior to any mercury capture tests, the inherent mercury content of the sample was determined by using a cold vapor atomic absorption (CVAA) spectrophotometer according to EPA method 7470. The inherent mercury content of the fly ash is the amount of mercury contained within the sample as it was received. It indicates the magnitude of mercury that was captured naturally by the ash sample during its formation as well as any mercury from the parent coal that was not liberated during combustion or gasification.

\section{Major and Minor Elemental Ash Chemistry}

The major and minor elemental ash chemistry analysis was determined by using a Leeman Labs PS3000UV inductively coupled plasma spectrometer (ICP). The sample was ashed at $900^{\circ} \mathrm{C}$ then dissolved by a lithium metaborate fusion procedure into a solution that was injected into the ICP.

\section{XPS Surface Chemistry}

Investigation into the surface chemistry of this sample was carried out by an XPS analysis. The

fly-ash powder was prepared by lightly pressing the powder onto a $3 \mathrm{M}$ double-sided tape with a mortar and pestle. Loose powder was blown free with dry $\mathrm{N}_{2}$ and then transferred to a sample plate for analysis. Uniform coverage of the $3 \mathrm{M}$ tape was verified using a stereo microscope. XPS quantification was performed by applying the appropriate relative sensitivity factors (RSFs) for the Kratos instrument to the integrated peak areas using linear background subtraction per ASTM method E 995. 


\section{Mercury Capture Studies}

A test rig at the University of Nottingham was utilized to test the sample for its mercury uptake capacity using atomic adsorption spectroscopy (AAS), operated in cold vapor mode ${ }^{5}$ The system is designed to ensure a continuous flow of nitrogen through the mercury vapor generator bottles and the AAS, which minimizes fluctuations in the concentration of mercury generated ${ }^{5}$.

For this project, special sorbent tubes were designed with a diameter of $8.5 \mathrm{~cm}$ and a fixed bed length of $2 \mathrm{~cm}$ in order to decrease the pressure build-up behind the sample tube. Pressure buildup was being experienced due to the very small particle size of some comparable fly ash samples being tested in the rig. The very fine particles were migrating through the standard sample tubes to eventually block the flow of vapor completely. A limiting flow rate of $40 \mathrm{~mL} / \mathrm{min}$ for the $\mathrm{Hg}$ saturated nitrogen vapor was determined using the newly designed sample tubes and the smallest sized samples.

\section{RESULTS AND DISCUSSION}

\section{Sample Characterization}

This section presents the characterization of the char sample, including the inherent mercury content, the ash chemistry, and the XPS surface chemistry.

\section{Inherent Mercury Content}

The inherent mercury content of the sample was measured using a CVAA method according to EPA method 7470. The amount of mercury contained in the sample as it was received was 0.04 $\mathrm{ppm}$. Compared to other fly ash samples with inherent mercury contents ranging from 0.01 to $0.81 \mathrm{ppm}$, this sample had a relatively low inherent mercury content.

\section{Major and Minor Elemental Ash Chemistry}

Table 3.1 displays the results of the ICP ash chemistry analysis for the sample. Very low concentrations of $\mathrm{BaO}, \mathrm{K}_{2} \mathrm{O}, \mathrm{MgO}, \mathrm{MnO}, \mathrm{Na}_{2} \mathrm{O}, \mathrm{P}_{2} \mathrm{O}_{5}, \mathrm{SrO}$, and $\mathrm{TiO}_{2}$ were measured. The sample had relatively low concentrations of $\mathrm{Al}_{2} \mathrm{O}_{3}$ and $\mathrm{CaO}$ compared to other fly ash samples analyzed in the same way, which ranged from $1.1 \%$ to $19.5 \% \mathrm{Al}_{2} \mathrm{O}_{3}$ by weight and $0.6 \%$ to $24.1 \% \mathrm{CaO}$ by weight. The silicon oxide concentration measured was moderate compared to 
other samples, ranging from $3.3 \%$ to $42.9 \% \mathrm{SiO}_{2}$ by weight. The amount of iron oxide determined in the sample was higher than that of other samples, which varied from $0.4 \%$ to $7.7 \%$ $\mathrm{Fe}_{2} \mathrm{O}_{3}$ by weight.

Table 3.1. ICP spectrochemical analyis reported in oxide percentages by weight (as-received)

\begin{tabular}{|cccccccccccc|}
\hline $\mathrm{Al}_{2} \mathrm{O}_{3}$ & $\mathrm{BaO}$ & $\mathrm{CaO}$ & $\mathrm{Fe}_{2} \mathrm{O}_{3}$ & $\mathrm{~K}_{2} \mathrm{O}$ & $\mathrm{MgO}$ & $\mathrm{MnO}$ & $\mathrm{Na}_{2} \mathrm{O}$ & $\mathrm{P}_{2} \mathrm{O}_{5}$ & $\mathrm{SiO}_{2}$ & $\mathrm{SrO}$ & $\mathrm{TiO}_{2}$ \\
\hline 9.5 & $--^{\mathrm{a}}$ & 2.6 & 8.4 & 0.7 & 0.5 & $-_{---^{\mathrm{a}}}$ & 0.4 & 0.1 & 20.9 & 0.1 & 0.5 \\
\hline
\end{tabular}

${ }^{\mathrm{a}}$ Below instrument detection level

\section{XPS Surface Chemistry}

Table 3.2 shows the concentration of elements on the surface of the sample as detected by an XPS analysis. The elements $\mathrm{Ti}, \mathrm{Na}, \mathrm{K}, \mathrm{Mg}, \mathrm{Ba}$, and $\mathrm{Co}$ were not found in any measurable surface concentrations. The concentration of carbon on the surface was relatively high at 71.5 atomic \% compared to other fly ashes, which ranged from 14.5 to 93.2 atomic \%. Nitrogen found on the surface of the sample was at the high end of the spectrum compared with other samples which ranged from $0.0-0.7$ atomic \%. The surface oxygen concentration was in the mid- to low range with other samples measuring 5.7-52.2 atomic \%. The amount of calcium and phosphorus detected on the surface were comparatively low compared to other samples ranging from 0.6-8.9 atomic \% Ca and 0.0-1.6 atomic \% P. Sulfur, fluorine, chlorine, and aluminum were of moderate values on the surface. Surface iron in the sample was the highest compared to other samples ranging from $0.0-1.6$ atomic $\%$.

Table 3.2. Concentration of elements detected on powders (in relative atomic \%)

\begin{tabular}{|ccccccccccc|}
\hline $\mathrm{C}$ & $\mathrm{N}$ & $\mathrm{O}$ & $\mathrm{S}$ & $\mathrm{F}$ & $\mathrm{Cl}$ & $\mathrm{Ca}$ & $\mathrm{Si}$ & $\mathrm{Al}$ & $\mathrm{P}$ & $\mathrm{Fe}$ \\
\hline 71.5 & 0.7 & 18.9 & 2.6 & 0.3 & 0.2 & 0.9 & 1.2 & 2.0 & 0.1 & 1.7 \\
\hline
\end{tabular}

\section{Mercury Capture Studies}

The mercury uptake capacity of the sample was determined using a mercury generation/capture rig and the results are presented in Table 3.3. The time to breakthrough indicates the length of time the sample adsorbs $100 \%$ of the mercury vapor that enters the inlet of the sample tube. The sample in this study demonstrated the best mercury capture performance compared to other fly 
ash samples tested in the same manner, with the next best sample adsorbing $3.00 \mathrm{mg} \mathrm{Hg} / \mathrm{g}$ sorbent over 19.78 hours.

Table 3.3. Mercury capture analysis

\begin{tabular}{|cccc|}
\hline $\begin{array}{c}\text { W, sample } \\
(\mathrm{g})\end{array}$ & $\begin{array}{c}\mathrm{t} \text {, breakthrough } \\
(\mathrm{hr})\end{array}$ & $\begin{array}{c}\text { Hg loading } \\
(\mathrm{mg} \mathrm{Hg})\end{array}$ & $\begin{array}{c}\text { Hg loading } \\
(\mathrm{mg} \mathrm{Hg} / \mathrm{g} \text { sorbent })\end{array}$ \\
\hline 0.491 & 45.79 & 3.6 & 7.30 \\
\hline
\end{tabular}

\section{CONCLUSIONS}

In this study, a gasification char sample was characterized using inherent mercury determination, ICP ash chemistry, and XPS surface chemistry analyses. The sample was also tested for its ability to capture mercury vapor. The char sample exhibited a low inherent mercury content at 0.04 ppm mercury, which is the amount of mercury contained within the sample as it was received.

The results of the major and minor ash chemistry analysis showed the sample had relatively low concentrations of $\mathrm{Al}_{2} \mathrm{O}_{3}$ and $\mathrm{CaO}$, at $9.5 \%$ and $2.6 \%$ by weight, respectively. A moderate concentration of $\mathrm{SiO}_{2}(20.9 \%$ by weight $)$ was found in the sample and the amount of $\mathrm{Fe}_{2} \mathrm{O}_{3}$ ( $8.4 \%$ by weight) was measured to be relatively high compared to other ash samples. Very low concentrations of $\mathrm{BaO}, \mathrm{K}_{2} \mathrm{O}, \mathrm{MgO}, \mathrm{MnO}, \mathrm{Na}_{2} \mathrm{O}, \mathrm{P}_{2} \mathrm{O}_{5}, \mathrm{SrO}$, and $\mathrm{TiO}_{2}$ were measured.

The XPS surface chemistry testing showed that the concentration of carbon atoms on the surface was relatively high at 71.5 atomic $\%$. Nitrogen atoms on the surface were also found to be at a relatively high concentration, measuring 0.7 atomic \%. Surface iron in the sample was the highest compared to other samples at 1.7 atomic \%. Moderately low values were determined for oxygen, calcium, and phosphorus. Relatively moderate values were measured for Sulfur, fluorine, chlorine, and aluminum. The elements $\mathrm{Ti}, \mathrm{Na}, \mathrm{K}, \mathrm{Mg}, \mathrm{Ba}$, and $\mathrm{Co}$ were not found in any measurable surface concentrations.

The char sample was found to have very good mercury capture performance. It adsorbed 7.30 $\mathrm{mg} \mathrm{Hg} / \mathrm{g}$ sorbent without experiencing breakthrough until after 45.8 hours of adsorbing. Most of 
the other ash samples tested on the same mercury generation/capture rig were shown to adsorb far less mercury and experienced much shorter times to breakthrough. Overall, this char sample is an effective mercury sorbent candidate prior to any sorbent-enhancing modifications.

\section{REFERENCES}

1. U.S.EPA., 2005, www.epa.gov/air/mercuryrule.

2. Brown, T.D.; Smith, D.N.; O’Dow, W.J.; Hargis, R.A.; Fuel Proc. Tech, 2000, 65, 311.

3. Maroto-Valer, M..M.; Zhang Y.; Granite E.J.; Tang Z.; Pennline H.W., Fuel, 2005, 84,105.

4. Maroto-Valer, M.M., Zhang,Y. Miller, B.G, Granite E.J., Tang Z, and Pennline H.W., Proceedings Carbon 2004, L035.pdf.

5. Snape, C.E., Contribution from the University of Nottingham: Hg Test Rig Report, March 24, 2005. 


\section{FUTURE WORK}

Work is progressing as per the task schedule previously established. In the coming year, UK will concentrate on finishing $\mathrm{Hg}$-sorption testing of activated char samples under simulated flue gas conditions. Work will also be concluded on the suitability of the highest carbon content fractions as conductive fillers in plastics. In particular, the activated carbon generated from the gasifier char carbon at PSU via steam activation will be tested for $\mathrm{Hg}$ and $\mathrm{NO}_{\mathrm{X}}$ adsorption potential. Samples will be tested at both UK and at PSU. All parent gasifier slag carbons will be tested for $\mathrm{NO}_{\mathrm{X}}$ adsorption potential and the best $\mathrm{Hg}$ adsorbing carbons will be tested for $\mathrm{Hg}$ in a simulated flue gas at UK.

Mercury loaded char samples will be subjected to leaching analysis to determine any determental release of $\mathrm{Hg}$ from these samples under storage conditions. Finally, PSU will undertake determination of the suitability of the high carbon content samples as replacements for bulk carbon fines in filling carbon bodies (as a coke replacement). 